\title{
Assessment of dietary fish consumption in pregnancy: comparing one-, four- and thirty-six-item questionnaires
}

\author{
Emily Oken ${ }^{1}$ *, Lauren B Guthrie ${ }^{1}$, Arienne Bloomingdale ${ }^{1}$, Matthew W Gillman 1,2, \\ Sjurdur F Olsen ${ }^{2}$, Chitra J Amarasiriwardena ${ }^{3}$, Deborah N Platek ${ }^{4}$, David C Bellinger ${ }^{5}$ \\ and Robert $\bigcirc$ Wright ${ }^{5,6}$ \\ 'Department of Population Medicine, Harvard Medical School and the Harvard Pilgrim Health Care Institute, \\ 133 Brookline Avenue, Boston, MA 02215, USA: ${ }^{2}$ Department of Nutrition, Harvard School of Public Health, \\ Boston, MA, USA: ${ }^{3}$ Department of Environmental Health, Harvard School of Public Health, Boston, MA, USA: \\ ${ }^{4}$ Department of Obstetrics and Gynecology, Harvard Vanguard Medical Associates, Boston, MA, USA: \\ ${ }^{5}$ Children's Hospital Boston, Boston, MA, USA: ${ }^{6}$ Channing Laboratory, Brigham and Women's Hospital, \\ Boston, MA, USA
}

Submitted 3 August 2012: Final revision received 18 March 2013: Accepted 8 May 2013: First published online 24 July 2013

\begin{abstract}
Objective: Fish consumption influences a number of health outcomes. Few studies have directly compared dietary assessment methods to determine the best approach to estimating intakes of fish and its component nutrients, including DHA, and toxicants, including methylmercury. Our objective was to compare three methods of assessing fish intake.

Design: We assessed $30 \mathrm{~d}$ fish intake using three approaches: (i) a single question on total fish consumption; (ii) a brief comprehensive FFQ that included four questions about fish; and (iii) a focused FFQ with thirty-six questions about different finfish and shellfish.

Setting: Obstetrics practices in Boston, MA, USA.

Subjects: Fifty-nine pregnant women who consumed $\leq 2$ monthly fish servings. Results: Estimated intakes of fish, DHA and Hg were lowest with the one-question screener and highest with the thirty-six-item fish questionnaire. Estimated intake of DHA with the thirty-six-item questionnaire was 4.4-fold higher (97v. $22 \mathrm{mg} / \mathrm{d}$ ), and intake of $\mathrm{Hg}$ was $3 \cdot 8$-fold higher $(1.6 v .0 .42 \mu \mathrm{g} / \mathrm{d})$, compared with the one-question screener. Plasma DHA concentration was correlated with fish intake assessed with the one-question screener (Spearman $r=0 \cdot 27, P=0 \cdot 04$ ), but not with the four-item FFQ $(r=0 \cdot 08, P=0 \cdot 54)$ or the thirty-six-item fish questionnaire $(r=0 \cdot 01, P=0 \cdot 93)$. In contrast, blood and hair $\mathrm{Hg}$ concentrations were similarly correlated with fish and $\mathrm{Hg}$ intakes regardless of the assessment method $(r=0.35$ to 0.52$)$.

Conclusions: A longer questionnaire provides no advantage over shorter questionnaires in ranking intakes of fish, DHA and $\mathrm{Hg}$ compared with biomarkers, but estimates of absolute intakes can vary by as much as fourfold across methods.
\end{abstract}

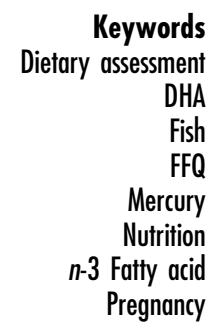

Recent studies have examined potential influences of dietary fish consumption for human health outcomes including pregnancy complications, child neurodevelopment and adult cardiovascular and neurological diseases $^{(1)}$. Most attention has focused on the role of fish as the primary route of exposure to methylmercury and also as the primary dietary source of the essential long-chain $n$-3 (omega-3) PUFA including DHA ${ }^{(1,2)}$. Earlier studies tended to examine associations of either $\mathrm{Hg}$ or $n$-3 PUFA exposure with health outcomes of interest (e.g. references 3 and 4), but with this harm-only or benefit-only approach it can be difficult to understand the net effect of fish intake. More recently, consensus has grown that studies should include information on diet as well as biomarkers of nutrients and toxicants to characterize best the overall health effects of fish consumption ${ }^{(5-10)}$ and provide balanced public health guidance.

Estimating fish consumption accurately is important to determining the proportion of women who are meeting current guidelines for intake of DHA $(>200 \mathrm{mg} / \mathrm{d})^{(11)}$ and $\mathrm{Hg}(<0 \cdot 1 \mu \mathrm{g} / \mathrm{kg} \text { body weight per } \mathrm{d})^{(12)}$ during pregnancy. Investigators have applied many different methods of assessing fish intake, including direct observation, food records, $24 \mathrm{~h}$ recalls and focused or comprehensive FFQ. Additionally, instruments have included different numbers of questions about fish intake, ranging from a 
single dichotomous measure to several dozen questions about individual fish dishes or species ${ }^{(13-18)}$. Shorter questionnaires confer less participant burden, but concern exists that these brief questionnaires may be less valid for assessing nutrient and contaminant intakes.

While studies often provide information regarding validation of the method used, few have directly compared methods to determine the approach best suited to estimating intakes of fish and its component toxicants and nutrients. Furthermore, these studies have focused on associations of fish intake with either toxicants or nutrients, but not both simultaneously ${ }^{(15,19,20)}$.

At the baseline visit of a pilot randomized trial to promote healthful fish intake in pregnancy ${ }^{(21)}$, we assessed dietary fish intake using three approaches: (i) a single screening question; (ii) an FFQ with four questions about fish; and (iii) a detailed questionnaire with thirty-six questions about different finfish and shellfish. Upon initial review of our baseline data, we noted substantial differences in the estimates of fish, DHA and $\mathrm{Hg}$ intakes ascertained using these three methods. Therefore, we undertook analyses to compare these dietary assessment methods and validate each against biomarkers of $\mathrm{Hg}$ and n-3 PUFA. We hypothesized that estimates of intake from the longer, more detailed instrument would be more strongly associated with biomarker concentrations.

\section{Materials and methods}

\section{Study design}

The present paper reports a cross-sectional analysis of data collected at entry into a pilot randomized controlled trial to promote consumption of low-Hg, high-DHA fish in pregnancy $^{(21)}$ (registered on clinicaltrials.gov as NCT01126762).

\section{Participants and procedures}

In April to October 2010 we recruited women residing in the greater Boston, MA area using advertisements posted in local obstetrics practices, newspapers, parenting listservs and other locations likely to be frequented by pregnant women (e.g. playgrounds, toy stores).

Interested women contacted us via telephone or email. A research assistant interviewed respondents via telephone to describe the study in detail, screen for eligibility and collect demographic information. Eligibility criteria for the randomized controlled trial (and also for the current analysis) included age $\geq 18$ years, singleton pregnancy, gestational age at enrolment $<23$ weeks and plans to stay in the Boston area through delivery. Because we were interested in targeting women with low fish consumption for the parent randomized controlled trial, whose goal was to increase intake of DHA from fish, we included only women who reported consuming fish up to two times per month, but who had no contraindications to fish consumption such as allergy or self-restrictions such as vegetarian diet. So that potential participants were not aware of the study's particular focus on fish, the screening questionnaire also queried other components of diet including intake of fruits and vegetables, dairy, nuts and meat.

Of 288 respondents, 215 did not meet inclusion criteria, most often because they reported consuming fish more than twice per month ( $n 155,72 \%)$ or were already at least 23 weeks' gestation ( $n$ 34, $16 \%$ ). Only four women declined participation, and another eight subsequently became ineligible (by failing to schedule the baseline study visit before 23 weeks' gestation, having a miscarriage or learning of a twin gestation), leaving sixty-one eligible participants.

At the baseline study visit, which we conducted in our research offices in Boston or at the participants' home or office (mean $2 \cdot 3$ weeks after the screener was administered), the research assistant obtained written informed consent and administered an interview to collect information on pregnancy history, health, sociodemographic characteristics and diet. We also collected blood via venepuncture for $\mathrm{Hg}$ and fatty acid analysis. We were unable to obtain blood at baseline from two women despite two attempts, and therefore include fifty-nine women in the current analysis.

We queried the type, brand and frequency of all supplements taken. We obtained blood via phlebotomy. We then randomized women to a 12 -week intervention to promote consumption of low-Hg, high-DHA fish or dietary advice not focused on fish. At the completion of the baseline visit, we provided women with a \$US 25 gift card and a fabric shopping bag with the study logo. At a follow-up visit 12 weeks after recruitment, we obtained a full-length sample of hair from the occipital scalp.

The study was conducted according to the guidelines described in the Declaration of Helsinki and all procedures involving human subjects were approved by the Harvard Pilgrim Health Care Human Subjects Committee. All participants provided written informed consent.

\section{Dietary measures}

We assessed fish consumption in three ways. First, on the screening telephone call the research assistant asked women 'During the past month, how many times have you eaten the following foods?' and then separately queried intake of vegetables, luncheon meats, nuts and 'fish, including shellfish - please also include any canned tuna, breaded fish products or shrimp'. We then asked about food allergies, any other food restrictions ('for example, for religious or other reasons'), whether women were vegetarian or vegan, and whether they would ever eat fish (among other listed foods).

Second, at the baseline in-person study visit, we queried diet using PrimeScreen, a brief FFQ that has been comprehensively validated in non-pregnant adults ${ }^{(22)}$, 
that includes twenty-one questions on diet during the past $30 \mathrm{~d}$, including four questions on intake of 'canned tuna fish', 'dark meat fish, for example mackerel, salmon, sardines, bluefish or swordfish', 'other fish, for example cod, haddock or halibut' and 'shrimp, lobster, scallops or clams as a main dish'. Six response categories ranged from 'never' to 'nearly daily or daily'. These questions are similar to those used in a longer semi-quantitative FFQ (SFFQ) that has been extensively validated in pregnant and non-pregnant adults and that we and others have used to examine associations of dietary fish and longchain $n$-3 PUFA intakes with a large number of health outcomes (e.g. references 6, 7, 23-27). Differences are that PrimeScreen is shorter (21 v.>100 questions) and does not include a serving size of the food consumed. Also we used a different time referent, i.e. 1 month $v$. the 3 months or 1 year typically used in studies with the full-length SFFQ.

Third, also at the baseline visit, we administered a fishfocused FFQ that queried intake of twenty-five specified types of finfish and eleven types of shellish/bivalves. We based our instrument on a thirty-two-item one used in the National Health and Nutrition Examination Survey (NHANES $^{(2,14,28)}$ that has been found to correlate with Hg levels ( $r=0.54$ for the association between quantity of fish and shellfish eaten and blood total $\mathrm{Hg}$ ), but was not compared with blood fatty acid levels ${ }^{(14)}$. We included an additional four fish types likely to be consumed in our geographic area, based on our preliminary research ${ }^{(29)}$. We asked women to report the number of times they had eaten each of the thirty-six fish types during the previous $30 \mathrm{~d}$. In addition, because the NHANES instrument did not obtain information on serving size ${ }^{(14)}$, we also asked women to report the number of ounces per serving of each type for which they reported any consumption. We provided models for different servings sizes (e.g. $1 \mathrm{oz}, 3 \mathrm{oz}$ ) to help women with their estimations. We asked women who had reported consumption of canned tuna whether they had eaten white, chunk light or both.

\section{Estimation of dietary DHA and Hg intakes}

We estimated daily intake of DHA from supplements based upon the dose and frequency of consumption. If the woman provided information on the brand of supplement but not the exact dose, we obtained DHA concentration from the manufacturer. For women $(n 5)$ for whom we had information on DHA supplement frequency but not dose or brand, we assigned the median value of supplement DHA reported in the study population $(200 \mathrm{mg} /$ dose $)$. For each of the three methods of dietary assessment, we calculated daily intake of DHA (mg/d) from fish and from fish + supplements, and $\mathrm{Hg}$ from fish $(\mu \mathrm{g} / \mathrm{d})$, as detailed below. We also calculated intake of each per kg body weight per day, using selfreported pre-pregnancy weight.
For the thirty-six-item fish questionnaire, we estimated concentration of DHA in each fish type using the US Department of Agriculture's nutrient database ${ }^{(30)}$ and total $\mathrm{Hg}$ in the fish using data provided by the Food and Drug Administration $^{(31)}$, or from a publication by Groth $^{(32)}$ for fish types not included in the Food and Drug Administration report. We multiplied the number of servings by the reported serving size for each fish type and summed intake across all fish consumed.

For the four PrimeScreen questions on fish, we identified weights for the different fish types included in each of the groups using the thirty-six-item questionnaire results. For example, 'dark meat fish' was $20 \%$ anchovies, $1 \%$ mackerel, $64 \%$ salmon, $14 \%$ sardines and $1 \%$ trout. We assumed a $113 \mathrm{~g}(4 \mathrm{oz})$ serving size for each of the four groups, based on the response categories used in the parent SFFQ from which we derived our instrument ${ }^{(33,34)}$. For each serving, we assigned concentrations of DHA ( $460 \mathrm{mg}$ for canned tuna, $1406 \mathrm{mg}$ for dark fish, $313 \mathrm{mg}$ for other fish and $232 \mathrm{mg}$ for shellfish) and $\mathrm{Hg}(25 \cdot 8 \mu \mathrm{g}$ for canned tuna, $2 \cdot 2 \mu \mathrm{g}$ for dark fish, $4 \cdot 8 \mu \mathrm{g}$ for other fish and $2 \cdot 4 \mu \mathrm{g}$ for shellfish). As a secondary approach, we also assigned DHA concentrations to each of the four fish groups based on older reference data used by other studies that assessed diet with a similar $\mathrm{FFQ}^{(7,25,35)}$.

Finally, we used a similar approach to weight each of the four fish categories and thereby estimate intakes of DHA and $\mathrm{Hg}$ using the single question on fish intake administered at the screening telephone call. Based on responses to the PrimeScreen, we assigned proportions of $33 \%$ canned tuna, $20 \%$ dark meat fish, $22 \%$ other fish and $25 \%$ shellish to each fish serving, similar to what has been done in other studies ${ }^{(25)}$.

\section{Bioassays}

We refrigerated all blood samples immediately after collection, and processed and stored them at $-80^{\circ} \mathrm{C}$ within $24 \mathrm{~h}$. We collected and stored whole blood in trace element-free tubes for Hg assay. We stored hair tied at the proximal end in paper envelopes at room temperature. We measured $\mathrm{Hg}$ in the proximal $3 \mathrm{~cm}$ of hair, which reflects $\mathrm{Hg}$ deposited approximately $30-120 \mathrm{~d}$ prior to collection (the most recent $30 \mathrm{~d}$ growth remains below the scalp). Hair is a recommended biomarker for estimating the methylmercury dose received by the offspring's brain ${ }^{(36)}$, and hair $\mathrm{Hg}$ is strongly associated with both maternal blood and cord blood organic $\mathrm{Hg}^{(37)}$. Since we collected hair at the follow-up visit ( $\sim 12$ weeks or $84 \mathrm{~d}$ after the baseline dietary assessment), the hair $\mathrm{Hg}$ content should have overlapped with the baseline dietary assessment. We measured total $\mathrm{Hg}$ in whole blood and hair using the Direct Mercury Analyzer 80 (Milestone Inc., Monroe, CT, USA). Using standard samples, the relative standard deviation was $6 \cdot 2 \%$ for blood (interlaboratory study programme INSPQ, Laboratoire de Toxicologie, Quebec, Canada) and $2 \cdot 4 \%$ for hair (homogenized 
powdered hair; Institute of Geophysical and Geochemical Exploration, Langfang, China). We detected $\mathrm{Hg}$ concentrations as low as $0 \cdot 3 \mu \mathrm{g} / \mathrm{g}$ with a minimum sample weight of $0 \cdot 2 \mathrm{~g}$.

We centrifuged whole blood collected in lithium heparin tubes at $2000 \mathrm{rpm}(650 \mathrm{~g})$ at $4^{\circ} \mathrm{C}$ for $10 \mathrm{~min}$ and stored plasma for fatty acid assay. Fatty acids were extracted and quantified in a single run using GLC on a fused silica capillary cis/trans column (SP2560; Supelco Inc., Belefonte, PA, USA) ${ }^{(38)}$. Peak retention times from forty peaks and area percentage of total fatty acids were identified by injecting standards (NuCheck Prep, Elysium, MN, USA) and using Agilent Technologies ChemStation A.08.03 software for analysis. With this method, the minimum reliable normalized percentage area was $0 \cdot 05 \%$ and the within-run CV for DHA was $4 \cdot 1 \%$.

\section{Data analysis}

We calculated means and distributions for continuous variables and proportions for categorical values. Because all measures of fish and DHA intake were not normally distributed, we determined Spearman correlation coefficients of the dietary intake estimates with each other and with biomarkers of DHA and Hg. To evaluate discrepancies in intakes of DHA and $\mathrm{Hg}$ from fish between the four-item and thirty-six-item questionnaires, we used Bland-Altman plots $^{(39)}$.

We performed all analyses using the statistical software package SAS version 9.3.

\section{Results}

Among the fifty-nine women included in the present analysis, mean age was $30 \cdot 2$ (SD 5.8) years, mean gestational age at recruitment was $17 \cdot 1$ (SD 3.8) weeks and mean pre-pregnancy BMI was $25.6(\mathrm{sD} 6 \cdot 0) \mathrm{kg} / \mathrm{m}^{2}$. The study population was of diverse income, race/ethnicity and educational attainment (Table 1). In Table 2 we report intakes of fish for all of the consumption questions we asked, i.e. the one-question screener, the four-item PrimeScreen and the thirty-six-item fish questionnaire. We also report the concentrations of DHA and $\mathrm{Hg}$ we used for each question. The four individual fish types with the highest mean monthly intake on the thirty-six-item fish questionnaire were tuna, breaded fish, salmon and shrimp (Table 2). One woman reported consuming shark, which pregnant women are advised to avoid entirely during pregnancy ${ }^{(40)}$, and one reported consuming mackerel, which may be either high or relatively low in $\mathrm{Hg}$, depending on the type and origin ${ }^{(40,41)}$.

Mean estimated intakes of fish, DHA and $\mathrm{Hg}$ were lowest with the one-question screener and highest with the thirty-six-item fish questionnaire (Table 3). For example, estimated intake of DHA with the thirty-six-item fish questionnaire was 4.4-fold higher (97 v. $22 \mathrm{mg} / \mathrm{d}$ ),
Table 1 Baseline characteristics of participants: fifty-nine pregnant women enrolled in the Food for Thought Study, Boston, MA, USA, April-October 2010

\begin{tabular}{|c|c|c|}
\hline Characteristic & Mean or $n$ & SD or $\%$ \\
\hline Age (years) ${ }^{*}$ & $30 \cdot 2$ & $5 \cdot 8$ \\
\hline Gestational age at baseline visit (weeks)* & $17 \cdot 1$ & $3 \cdot 8$ \\
\hline Pre-pregnancy BMI $\left(\mathrm{kg} / \mathrm{m}^{2}\right)^{*}$ & $25 \cdot 6$ & $6 \cdot 0$ \\
\hline \multicolumn{3}{|l|}{ Marital status } \\
\hline Married & 34 & 58 \\
\hline Single & 14 & 24 \\
\hline Single, living with partner & 11 & 19 \\
\hline Nulliparous & 17 & 29 \\
\hline \multicolumn{3}{|l|}{ Race/ethnicity } \\
\hline White & 28 & 47 \\
\hline Black & 9 & 15 \\
\hline Asian & 6 & 10 \\
\hline Hispanic & 3 & 5 \\
\hline More than one race & 13 & 22 \\
\hline \multicolumn{3}{|l|}{ Employment } \\
\hline Working full time & 22 & 37 \\
\hline Working part time & 8 & 14 \\
\hline Student/stay at home/not working & 17 & 29 \\
\hline Looking for work & 12 & 20 \\
\hline \multicolumn{3}{|l|}{ Annual household income (\$US) } \\
\hline$<40000$ & 22 & 37 \\
\hline $40001-70000$ & 13 & 22 \\
\hline $70001-100000$ & 10 & 17 \\
\hline $100001-150000$ & 6 & 10 \\
\hline$\geq 150001$ & 6 & 10 \\
\hline Don’t know & 2 & 3 \\
\hline \multicolumn{3}{|l|}{ Education } \\
\hline High school or less & 8 & 14 \\
\hline Some college & 17 & 29 \\
\hline College graduate & 34 & 58 \\
\hline \multicolumn{3}{|l|}{ Smoking history } \\
\hline Smoked during pregnancy & 7 & 12 \\
\hline Former smoker & 11 & 19 \\
\hline Never smoker & 41 & 69 \\
\hline
\end{tabular}

*These data are presented as mean and standard deviation; all other data are presented as number and percentage.

and intake of $\mathrm{Hg}$ was 3.8-fold higher $(1 \cdot 60 v .0 \cdot 42 \mu \mathrm{g} / \mathrm{d})$, compared with the one-question screener.

The Bland-Altman plot for intake of DHA showed that most of the mean differences were positive, i.e. DHA intake was consistently higher when reported via the thirty-sixitem questionnaire $v$, the four-item instrument (Fig. 1). Differences increased with greater mean DHA intake. For $\mathrm{Hg}$, however, the mean difference was substantially closer to zero, suggesting that women both under- and overestimated their $\mathrm{Hg}$ intake on the thirty-six-item questionnaire relative to the four-item questionnaire (Fig. 2).

By design, none of the women reported consuming $>2$ monthly fish servings on the screener, whereas twentyseven $(46 \%)$ of the same women reported $>2$ monthly servings on the PrimeScreen and forty-nine (83\%) on the thirty-six-item questionnaire. Accordingly, the proportion of women who consumed the recommended $200 \mathrm{mg}$ DHA/d from combined foods and supplements varied by dietary assessment method: one-question screener $0 \%$, four-question PrimeScreen $27 \%$, thirty-six-item fish questionnaire $36 \%$. Correlations between pairs of dietary assessment methods for total fish intake were highest for 
Table 2 Frequency of consumption of fish (including finfish and shellfish) assessed by three methods of dietary assessment, and the concentrations of DHA and mercury assigned to each type, among fifty-nine pregnant women enrolled in the Food for Thought Study, Boston, MA, USA, April-October 2010

\begin{tabular}{|c|c|c|c|c|c|c|c|c|}
\hline \multirow[b]{2}{*}{ Types of fish } & \multirow{2}{*}{$\begin{array}{l}\text { No. of women } \\
\text { reporting any intake }\end{array}$} & \multicolumn{2}{|c|}{$\begin{array}{l}\text { Amount consumed } \\
\text { per serving }(\mathrm{g})^{*}\end{array}$} & \multicolumn{2}{|c|}{$\begin{array}{l}\text { Frequency of intake } \\
\text { (servings/month) }^{*}\end{array}$} & \multirow{2}{*}{$\begin{array}{l}\text { Mean intake among } \\
\text { all women ( } \mathrm{g} / \text { month) }\end{array}$} & \multirow{2}{*}{$\begin{array}{c}\text { DHA } \\
\text { (mg/100 g fish) }\end{array}$} & \multirow{2}{*}{$\underset{(\mu \mathrm{g} / \mathrm{g} \text { fish) }}{\mathrm{Hg}}$} \\
\hline & & Mean & Range & Mean & Range & & & \\
\hline \multicolumn{9}{|l|}{ One-question screener } \\
\hline Total fish consumption by screener & 41 & $113+$ & - & $1 \cdot 6$ & $1-2$ & 126 & 497 & 0.092 \\
\hline \multicolumn{9}{|l|}{ Four-question PrimeScreen FFQ } \\
\hline Canned tuna fish & 28 & $113+$ & - & $2 \cdot 4$ & $1-12$ & 126 & 406 & $0 \cdot 228$ \\
\hline Dark meat fish & 23 & $113 t$ & - & $2 \cdot 5$ & $1-24$ & 111 & 1240 & 0.020 \\
\hline Other fish & 24 & $113+$ & - & $1 \cdot 6$ & $1-4$ & 72 & 276 & 0.042 \\
\hline Shrimp \& other shellfish & 25 & $113+$ & - & $2 \cdot 4$ & $1-12$ & 117 & 204 & 0.021 \\
\hline Total fish consumption by PrimeScreen FFQ & 48 & - & - & $4 \cdot 6$ & $1-36$ & 426 & - & - \\
\hline \multicolumn{9}{|l|}{ Thirty-six-item fish FFQ } \\
\hline \multicolumn{9}{|l|}{ Finfish } \\
\hline Anchovies & 5 & 68 & $28-170$ & $4 \cdot 8$ & $1-14$ & 19 & 1292 & $0 \cdot 017$ \\
\hline Breaded fish products & 16 & 136 & $57-227$ & $2 \cdot 2$ & $1-4$ & 77 & 303 & 0.021 \\
\hline Bass & 3 & 122 & $85-170$ & $1 \cdot 7$ & $1-2$ & 11 & 458 & $0 \cdot 152$ \\
\hline Catfish & 2 & 85 & - & 1.5 & $1-2$ & 0 & 69 & 0.025 \\
\hline Cod & 8 & 85 & $57-170$ & $2 \cdot 0$ & $1-4$ & 25 & 154 & 0.011 \\
\hline Flatfish & 1 & 170 & - & $2 \cdot 0$ & & 6 & 132 & 0.056 \\
\hline Haddock & 10 & 156 & 85-199 & $1 \cdot 4$ & $1-3$ & 38 & 109 & 0.055 \\
\hline Herring & 0 & - & - & - & - & 0 & 1105 & 0.084 \\
\hline Mackerel & 1 & 57 & - & $2 \cdot 0$ & - & 2 & 699 & 0.050 \\
\hline Perch & 1 & 85 & - & $1 \cdot 0$ & - & 1 & 186 & $0 \cdot 121$ \\
\hline Pike & 0 & - & - & - & - & 0 & 85 & 0.056 \\
\hline Pollock & 0 & - & - & - & - & 0 & 451 & 0.031 \\
\hline Porgy & 1 & 170 & - & $1 \cdot 0$ & - & 6 & 273 & $0 \cdot 137$ \\
\hline Salmon & 19 & 108 & $28-256$ & $2 \cdot 0$ & $1-6$ & 72 & 1457 & 0.022 \\
\hline Salt cod/bacalao & 6 & 130 & $57-341$ & $2 \cdot 0$ & $1-4$ & 29 & 423 & 0.095 \\
\hline Sardines & 6 & 91 & $28-142$ & $2 \cdot 5$ & $1-5$ & 25 & 509 & 0.013 \\
\hline Sea bass & 0 & - & - & - & - & 0 & 556 & 0.354 \\
\hline Shark & 1 & 85 & - & $1 \cdot 0$ & - & 1 & 431 & 0.979 \\
\hline Swordfish & 0 & - & - & - & - & 0 & 772 & 0.995 \\
\hline Trout & 1 & 57 & - & $1 \cdot 0$ & - & 1 & 677 & 0.071 \\
\hline Walleye & 0 & - & - & - & - & 0 & 288 & 0.065 \\
\hline Whitefish & 2 & 57 & - & $1 \cdot 0$ & - & 2 & 1206 & 0.089 \\
\hline Other types of fish & 7 & 111 & $28-170$ & $1 \cdot 1$ & $1-2$ & 14 & 130 & 0.013 \\
\hline Unknown type of fish & 2 & 71 & $57-85$ & $1 \cdot 0$ & - & 2 & 130 & 0.013 \\
\hline Tuna & 27 & 139 & $28-227$ & $1 \cdot 6$ & $1-4$ & 106 & & \\
\hline Tuna, canned light & - & - & - & - & - & - & 223 & $0 \cdot 128$ \\
\hline Tuna, canned white & - & - & - & - & - & - & 629 & 0.350 \\
\hline \multicolumn{9}{|l|}{ Shellfish } \\
\hline Clams & 17 & 111 & $28-341$ & $1 \cdot 4$ & $1-3$ & 51 & 146 & 0.009 \\
\hline Crab & 5 & 74 & $28-85$ & $1 \cdot 6$ & $1-2$ & 11 & 093 & 0.065 \\
\hline
\end{tabular}


the FFQ with the thirty-six-item questionnaire (Spearman $r=0.79, \quad P<0.0001)$, modest for the FFQ with the screener $(0.51, P<0 \cdot 0001)$ and lowest for the screener with the thirty-six-item questionnaire $(r=0 \cdot 37, P=0 \cdot 004)$.

Plasma DHA concentration was correlated with fish intake assessed with the one-question screener (Spearman $r=0.27, \quad P=0.04)$, but not with the four-question PrimeScreen $(r=0.08, P=0.54)$ or thirty-six-item fish questionnaire $(r=0.01, P=0.93)$. Correlations of plasma DHA with DHA intake from fish were somewhat stronger (Table 3), and even more so among the subset of women who did not report consuming any DHA supplements (data not shown) or when supplement intake was also included in DHA intake estimates (Table 3). The 'dark meat fish' question was the single PrimeScreen question most strongly correlated with plasma DHA $(r=0 \cdot 22$, $P=0 \cdot 10)$ and salmon was the individual fish type most strongly correlated with plasma DHA $(r=0 \cdot 24, P=0 \cdot 07)$.

In contrast to the plasma DHA results, blood and hair $\mathrm{Hg}$ concentrations were correlated ( $r=0.35$ to 0.52$)$ with fish intake and estimated $\mathrm{Hg}$ intake from fish regardless of the method of dietary assessment (Table 3). The shellfish question was the PrimeScreen question most strongly correlated with blood $\mathrm{Hg}(r=0.48, P=0.0001)$, and clams $(r=0.41, P=0.001)$ and lobster $(0.32, P=0.01)$ were the individual fish types most strongly correlated with blood $\mathrm{Hg}$. Blood and hair Hg levels were strongly correlated with each other $(r=0 \cdot 81, P<0 \cdot 0001)$, but less so with plasma DHA $(r=0 \cdot 16, P=0.24$ and $r=0 \cdot 26$, $P=0 \cdot 26$, respectively).

Intake of DHA from supplements was correlated with plasma DHA $(r=0 \cdot 29, P=0 \cdot 03)$, but not with $\mathrm{Hg}$ concentration in blood $(r=-0 \cdot 15, \quad P=0 \cdot 26)$ or hair $(r=-0 \cdot 01, P=0 \cdot 96)$. When we used intakes of DHA and Hg per kg body weight per day instead of absolute intake, correlations with all biomarkers were similar (data not shown). Estimated DHA intake from the four PrimeScreen questions was lower $(47 \mathrm{mg} / \mathrm{d})$ when we used a published algorithm based on fish landing data ${ }^{(25,35)}$ to assign DHA concentrations to each of the four questions, instead of the weights based on responses to the thirty-six-item questionnaire in this population $(69 \mathrm{mg} / \mathrm{d})$, but the correlation with plasma DHA was identical $(r=0 \cdot 14, P=0 \cdot 30)$.

\section{Discussion}

A questionnaire that included thirty-six questions on fish intake yielded substantially higher estimates of $30 \mathrm{~d}$ intakes of fish, DHA and Hg compared with methods incorporating fewer questions. However, correlations with biomarkers of Hg were similar regardless of the number of questions asked, and correlations with plasma DHA were lower for the methods that included more $v$. fewer questions.

Our Hg results were similar to those from a recent study by Strom et al. ${ }^{(15)}$, who administered both a single 
Table 3 Correlations of blood levels of DHA and mercury at baseline, and hair mercury at 12-week follow-up, with dietary intake of fish, DHA and mercury among fifty-nine pregnant women enrolled in the Food for Thought Study, Boston, MA, USA, April-October 2010

\begin{tabular}{|c|c|c|c|c|c|c|c|c|}
\hline \multirow[b]{2}{*}{ Method of assessment } & \multirow[b]{2}{*}{ Mean } & \multirow[b]{2}{*}{ SD } & \multicolumn{2}{|c|}{ Plasma DHA } & \multicolumn{2}{|c|}{ Blood $\mathrm{Hg}$} & \multicolumn{2}{|c|}{ Hair Hg } \\
\hline & & & $r$ & $P$ value & $r$ & $P$ value & $r$ & $P$ value \\
\hline \multicolumn{9}{|l|}{ Supplement questionnaire } \\
\hline DHA from supplements (mg/d, all 59 participants) & 70 & 113 & $0 \cdot 29$ & 0.03 & $-0 \cdot 15$ & $0 \cdot 26$ & -0.01 & 0.96 \\
\hline DHA from supplements ( $\mathrm{mg} / \mathrm{d}, 18$ participants taking supplements) & 228 & 74 & $0 \cdot 27$ & 0.28 & $0 \cdot 14$ & 0.59 & 0.00 & 0.99 \\
\hline \multicolumn{9}{|l|}{ One-question screener } \\
\hline Fish intake (servings/week) & $0 \cdot 28$ & $0 \cdot 21$ & $0 \cdot 27$ & 0.04 & $0 \cdot 38$ & 0.003 & 0.43 & $0 \cdot 001$ \\
\hline DHA from fish $(\mathrm{mg} / \mathrm{d})$ & 22 & 17 & $0 \cdot 27$ & 0.04 & $0 \cdot 38$ & 0.003 & 0.43 & 0.001 \\
\hline Hg intake $(\mu \mathrm{g} / \mathrm{d})$ & 0.42 & 0.32 & $0 \cdot 27$ & 0.04 & $0 \cdot 38$ & 0.003 & 0.43 & $0 \cdot 001$ \\
\hline \multicolumn{9}{|l|}{ Four-question PrimeScreen FFQ } \\
\hline Fish intake (servings/week) & 0.9 & $1 \cdot 4$ & 0.08 & 0.54 & $0 \cdot 52$ & $<0.0001$ & 0.44 & 0.0008 \\
\hline DHA from fish $(\mathrm{mg} / \mathrm{d})$ & 69 & 186 & $0 \cdot 14$ & 0.29 & $0 \cdot 39$ & 0.002 & $0 \cdot 42$ & 0.001 \\
\hline DHA from fish + supplements $(\mathrm{mg} / \mathrm{d})$ & 138 & 205 & 0.33 & $0 \cdot 01$ & 0.08 & 0.44 & $0 \cdot 21$ & $0 \cdot 13$ \\
\hline Hg intake $(\mu \mathrm{g} / \mathrm{d})$ & $1 \cdot 25$ & $2 \cdot 47$ & -0.05 & $0 \cdot 70$ & 0.46 & 0.0002 & $0 \cdot 42$ & 0.002 \\
\hline \multicolumn{9}{|l|}{ Thirty-six-item fish FFQ } \\
\hline Fish intake (servings/week) & $3 \cdot 2$ & $3 \cdot 3$ & 0.01 & 0.93 & 0.46 & 0.0002 & 0.35 & 0.009 \\
\hline Fish intake (4 oz (113g) servings/week) & $1 \cdot 4$ & $1 \cdot 7$ & 0.03 & $0 \cdot 80$ & 0.46 & 0.0002 & 0.32 & 0.02 \\
\hline DHA from fish $(\mathrm{mg} / \mathrm{d})$ & 97 & 117 & $0 \cdot 14$ & $0 \cdot 30$ & $0 \cdot 46$ & 0.0002 & $0 \cdot 34$ & 0.01 \\
\hline DHA from fish + supplements $(\mathrm{mg} / \mathrm{d})$ & 166 & 154 & $0 \cdot 30$ & 0.03 & $0 \cdot 18$ & $0 \cdot 17$ & $0 \cdot 21$ & $0 \cdot 13$ \\
\hline Hg intake $(\mu \mathrm{g} / \mathrm{d})$ & $1 \cdot 6$ & $2 \cdot 2$ & -0.07 & $0 \cdot 60$ & $0 \cdot 48$ & 0.001 & $0 \cdot 40$ & 0.003 \\
\hline \multicolumn{9}{|l|}{ Biomarkers } \\
\hline Plasma DHA (\% of total fatty acids) & 1.9 & 0.5 & $1 \cdot 00$ & - & - & - & - & - \\
\hline Whole blood Hg ( $\mu \mathrm{g} / \mathrm{l})$ & $1 \cdot 4$ & $1 \cdot 1$ & $0 \cdot 16$ & 0.24 & 1.00 & - & - & - \\
\hline Hair Hg (ng/g, n 54) & 0.29 & 0.28 & $0 \cdot 26$ & 0.06 & $0 \cdot 81$ & $<0.0001$ & 1.00 & - \\
\hline
\end{tabular}

$r$, Spearman correlation coefficient.

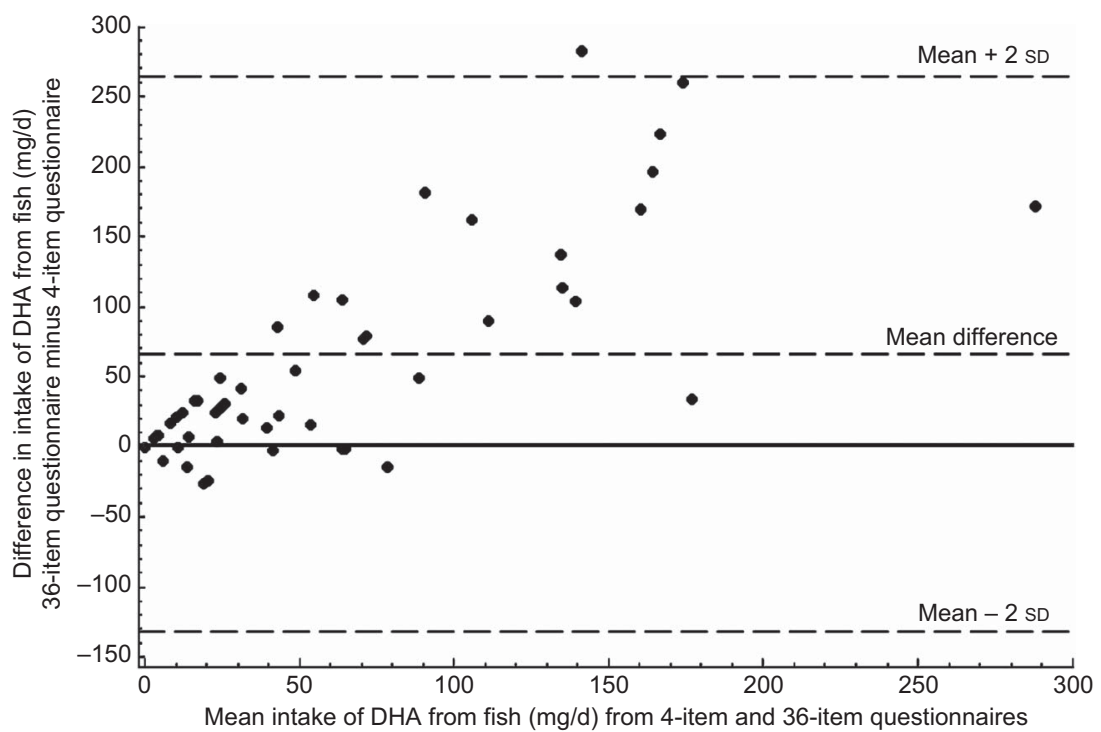

Fig. 1 Bland-Altman plot comparing DHA intake assessed by the four-item and the thirty-six-item FFQ among fifty-nine pregnant women enrolled in the Food for Thought Study, Boston, MA, USA, April-October 2010

question on total fish intake and a comprehensive FFQ with questions on sixteen different fish species to 1948 women living in coastal areas of Sweden. Fish consumption assessed by the FFQ was about twice as high as that assessed by the single question ( $8 \cdot 2 v .4 \cdot 0$ times/ month), but both were similarly correlated with hair $\mathrm{Hg}$ $(r=0.75$ for both). Among twenty-seven adults in New Hampshire, Rees et al. ${ }^{(19)}$ examined associations of toenail $\mathrm{Hg}$ concentration with three methods of dietary assessment: a 3 d food diary focused on fish; an SFFQ with four fish questions; and a detailed fish consumption questionnaire. Total fish consumption from the four SFFQ questions was the measure most strongly associated with Hg (Spearman $r=0.48$ ), whereas the other two dietary assessment methods were poorly correlated $(r=0 \cdot 20$ and $r=0 \cdot 16)$ with toenail $\mathrm{Hg}$. However, in contrast to our findings, they observed higher fish intake assessed by the SFFQ compared with the detailed questionnaire 


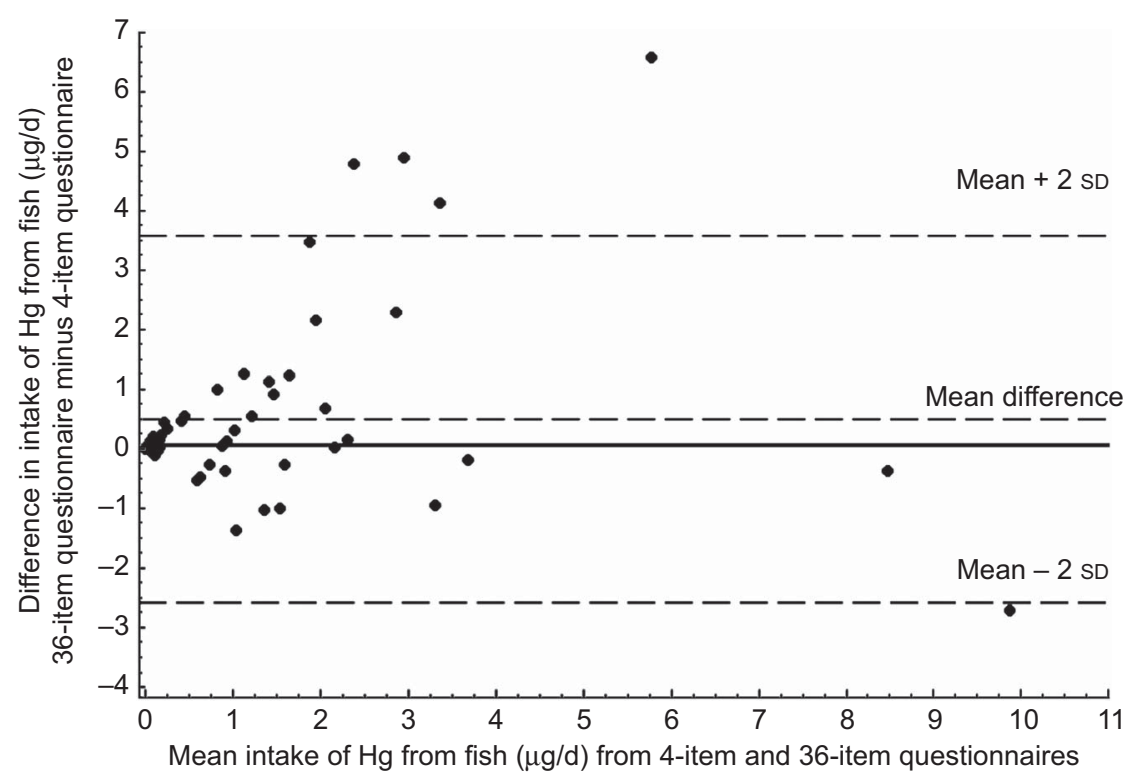

Fig. 2 Bland-Altman plot comparing mercury intake assessed by the four-item and the thirty-six-item FFQ among fifty-nine pregnant women enrolled in the Food for Thought Study, Boston, MA, USA, April-October 2010

$(1 \cdot 9 \text { v. } 1 \cdot 2 \text { servings/week })^{(19)}$. The reason for this discrepancy is not clear. Neither study estimated fatty acid intake, or measured fatty acid biomarkers.

Among 135 Danish women assessed in the 30th week of pregnancy, Olsen et al. ${ }^{(20)}$ found that intake of marine $n$-3 fatty acids estimated by three simple marine FFQ was comparable with intake estimated by an elaborate semi-quantitative dietary method involving an interview, based on correlations with erythrocyte $n-3$ fatty acid concentrations. However, that study did not estimate $\mathrm{Hg}$ intake or measure $\mathrm{Hg}$ levels, and did not compare absolute intakes of fish or fatty acids assessed with the different methods. In addition those results may not be generalizable to a US population, as fish intake patterns differ in Denmark $v$. the USA.

It is not surprising that we found somewhat higher correlations of dietary estimates with biomarkers of $\mathrm{Hg}$ compared with biomarkers of DHA. Fish is essentially the only dietary source for methylmercury intake, although exposure to inorganic $\mathrm{Hg}$ commonly occurs from dental amalgams $^{(1,42)}$. In contrast, while fish is the predominant food source for $n-3$ PUFA, other food sources include eggs and poultry ${ }^{(1)}$, and also supplements as in the current study. Also, shorter-chain n-3 PUFA can be elongated and desaturated to form DHA, which can be incorporated into prostaglandins and other eicosanoids. Therefore blood levels may reflect synthesis and metabolism as well as intake ${ }^{(43)}$. Furthermore, plasma fatty acid concentrations may be influenced by recently consumed meals. Others have suggested that levels of environmental contaminants, especially $\mathrm{Hg}$, are in fact a better biomarker for fish intake than levels of the long-chain 'marine' $n-3$ fatty acids ${ }^{(18)}$.
Concentration of DHA in erythrocytes or adipose tissue may better reflect longer-term intake of fish or $n-3$ PUFA compared with plasma ${ }^{(44)}$. However, since the time referent for all dietary methods used in our study was $30 \mathrm{~d}$, and in the parent trial we assessed change in intake over 12 weeks in response to the experimental intervention, we thought it appropriate to use plasma, a biomarker of shorter-term exposure. In other studies, correlations of dietary fish and DHA intake with erythrocyte levels of $n$-3 PUFA were in the range of $0 \cdot 3-0 \cdot 4^{(20,35)}$, similar to what we observed for correlations of plasma DHA concentration with the screener and for DHA from fish plus supplements using the other two methods.

There are several limitations to the present study. All women were pregnant and resided in the greater Boston, MA area and thus the results may not be generalizable to men or non-pregnant women or those living elsewhere. However, the population was of diverse racial/ethnic and socio-economic make-up. The small number of participants does not permit analysis by subgroup; however, in previous work we did not find that fatty acid correlations differed substantially by BMI or race/ethnicity ${ }^{(35)}$. By design we limited recruitment to low fish consumers, i.e. women who reported intake of $\leq 2$ monthly fish servings on the one-question screener, and therefore results may not be generalizable to frequent fish consumers. Nevertheless, estimates of mean daily intake using the fourquestion FFQ in our study were similar to those among women of childbearing age in the nationally representative US NHANES for fish (15v.13g), DHA (68v.62 mg) and $\mathrm{Hg}(1 \cdot 3 v \cdot 1 \cdot 2 \mu \mathrm{g})^{(1,14)}$. The four individual fish types (tuna, breaded fish, salmon and shrimp) with the highest mean monthly intake on the thirty-six-item fish 
questionnaire are also the four most highly consumed fish types in the $\mathrm{USA}^{(32)}$. Also, mean blood $\mathrm{Hg}$ in our population $(1.4 \mu \mathrm{g} / \mathrm{l})$ was similar to that in NHANES (geometric mean $0 \cdot 8 \mu \mathrm{g} / \mathrm{l}^{(14)}$ and plasma DHA concentration $(1.7 \%$ of total fatty acids) was similar to that in a large cohort of pregnant women also from Boston $(1.9 \% \text { of total fatty acids })^{(7)}$. Therefore, despite the inclusion restriction, our population had estimated fish consumption that was similar to reference populations not selected on the basis of fish intake.

The optimal method of assessing dietary fish intake depends on the goal of the assessment. If the main purpose is to rank individuals according to their intake of fish, DHA or $\mathrm{Hg}$, we find no evidence for an advantage of more over fewer questions. To illustrate this point, a recent publication found significant differences in levels of $\mathrm{Hg}$, lipids and inflammatory markers in children whose fish consumption was characterized as yes $v$. no ${ }^{(16)}$. However, if the main purpose is to estimate actual intake or intake above a given threshold, the answer is less clear, in part because we did not administer a reference method such as multiple-day $24 \mathrm{~h}$ recalls. It is possible that an instrument containing more questions about a larger number of fish types elicits a more accurate recall, or alternatively that the many questions prompt overreporting of intake. Nevertheless, it is important to recognize that the different methods yield such substantially different estimates - in this case, a more than fourfold difference in mean DHA and $\mathrm{Hg}$ intakes between the thirty-six-question and one-question versions - and a difference of $83 \% v .0 \%$ of women who reported eating fish more than twice per month.

Analyses of NHANES data collected since 1999 have used a $24 \mathrm{~h}$ recall to generate nationally representative estimates of daily intakes of fish, DHA and $\mathrm{Hg}^{(1,14)}$. While FFQ are generally more appropriate for ranking rather than assessing absolute intake ${ }^{(45)}$, the similarity of both estimated dietary intakes from the four FFQ questions and biomarker concentrations in our study $v$. NHANES suggests that a brief FFQ in a small sample provides similar results to a $24 \mathrm{~h}$ recall administered to a large population. Collection and analysis of dietary recall data is time-intensive and requires the expertise of a dietitian, compared with FFQ which are brief, self-administered and can be optically scanned ${ }^{(45,46)}$. However, as we did not directly compare these two methods in the same population, future work is needed to confirm the inference that an FFQ can reasonably estimate absolute fish intake.

\section{Conclusion}

We found that a longer questionnaire provides no advantage over shorter questionnaires in ranking intakes of fish, DHA and $\mathrm{Hg}$ compared with biomarkers, but estimates of absolute intakes can vary by as much as fourfold across methods. However, there still may be a role for more detailed questionnaires to characterize the relative contributions of different fish types to overall intake. For example, prior studies that found beneficial effects of maternal prenatal fish intake (assessed by FFQ) for child neurodevelopment ${ }^{(7,47)}$ were criticized $^{(48-50)}$ for lacking detailed information about the types of fish consumed, limiting the ability to provide advice to the public based on the study findings. We recommend that brief FFQ are the most appropriate instrument for estimating relative and possibly absolute intakes of fish, DHA and $\mathrm{Hg}$. The inclusion of more detailed questions about types and quantities of fish can inform generalization of study results and contribute useful information to governmental and other groups wishing to provide consumption advice to the public.

\section{Acknowledgements}

Sources of funding: This project was supported by the National Institutes of Health (grant numbers R01ES016314 and K24 HD069408), pilot project funding from the Harvard School of Public Health-National Institute of Environmental Health Sciences Center for Environmental Health (grant number P30 ES000002) and the Harvard Clinical Nutrition Research Center (grant number P30 DK040561), and by the Harvard Pilgrim Health Care Institute. Conflicts of interest: None of the authors has a conflict of interest to report. Authors' contributions: E.O., L.G.B., A.B., M.W.G., D.C.B. and R.O.W. designed the research; E.O., L.G.B., A.B., C.J.A. and D.N.P. conducted the research; L.G.B. and E.O. analysed the data; E.O. wrote the paper; E.O. had primary responsibility for final content. All authors read and approved the final manuscript. Acknowledgements: The authors appreciate the assistance with laboratory assays received from Jeremy Furtado, Nicola Lupoli and Innocent Jayawardena.

\section{References}

1. Nesheim M \& Yaktine A (2007) Seafood Choices: Balancing Benefits and Risks. Washington, DC: The National Academies Press.

2. Mahaffey KR, Clickner RP \& Jeffries RA (2008) Methylmercury and omega- 3 fatty acids: co-occurrence of dietary sources with emphasis on fish and shellfish. Environ Res 107, 20-29.

3. Debes F, Budtz-Jorgensen E, Weihe P et al. (2006) Impact of prenatal methylmercury exposure on neurobehavioral function at age 14 years. Neurotoxicol Teratol 28, 536-547.

4. Myers GJ, Davidson PW, Cox C et al. (2003) Prenatal methylmercury exposure from ocean fish consumption in the Seychelles child development study. Lancet 361, 1686-1692.

5. Stern AH \& Korn LR (2011) An approach for quantitatively balancing methylmercury risk and omega-3 benefit in fish consumption advisories. Environ Health Perspect 119, 1043-1046. 
6. Oken E \& Bellinger DC (2008) Fish consumption, methylmercury and child neurodevelopment. Curr Opin Pediatr 20, 178-183.

7. Oken E, Radesky JS, Wright RO et al. (2008) Maternal fish intake during pregnancy, blood mercury levels, and child cognition at age 3 years in a US cohort. Am J Epidemiol 167, 1171-1181.

8. Oken E, Wright RO, Kleinman KP et al. (2005) Maternal fish consumption, hair mercury, and infant cognition in a US cohort. Environ Health Perspect 113, 1376-1380.

9. Lynch ML, Huang LS, Cox C et al. (2010) Varying coefficient function models to explore interactions between maternal nutritional status and prenatal methylmercury toxicity in the Seychelles Child Development Nutrition Study. Environ Res 111, 75-80.

10. Budtz-Jorgensen E, Grandjean P \& Weihe P (2007) Separation of risks and benefits of seafood intake. Environ Health Perspect 115, 323-327.

11. Koletzko B, Cetin I \& Thomas Brenna J (2007) Dietary fat intakes for pregnant and lactating women. Br J Nutr $\mathbf{9 8}$, 873-877.

12. Goyer R, Aposhian V, Arab L et al. (2000) Toxicological Effects of Methylmercury. Washington, DC: National Academy Press.

13. Mahaffey KR, Clickner RP \& Jeffries RA (2009) Adult women's blood mercury concentrations vary regionally in the United States: association with patterns of fish consumption (NHANES 1999-2004). Environ Health Perspect 117, 47-53.

14. Mahaffey KR, Clickner RP \& Bodurow CC (2004) Blood organic mercury and dietary mercury intake: National Health and Nutrition Examination Survey, 1999 and 2000. Environ Health Perspect 112, 562-570.

15. Strom S, Helmfrid I, Glynn A et al. (2011) Nutritional and toxicological aspects of seafood consumption - an integrated exposure and risk assessment of methylmercury and polyunsaturated fatty acids. Environ Res 111, 274-280.

16. Gump BB, MacKenzie JA, Dumas AK et al. (2011) Fish consumption, low-level mercury, lipids, and inflammatory markers in children. Environ Res 112, 204-211.

17. Fillion M, Mergler D, Sousa Passos CJ et al. (2006) A preliminary study of mercury exposure and blood pressure in the Brazilian Amazon. Environ Health 5, 29.

18. Turunen AW, Mannisto S, Kiviranta H et al. (2010) Dioxins, polychlorinated biphenyls, methyl mercury and omega-3 polyunsaturated fatty acids as biomarkers of fish consumption. Eur J Clin Nutr 64, 313-323.

19. Rees JR, Sturup S, Chen C et al. (2007) Toenail mercury and dietary fish consumption. J Expo Sci Environ Epidemiol 17, $25-30$.

20. Olsen SF, Hansen HS, Sandstrom B et al. (1995) Erythrocyte levels compared with reported dietary intake of marine $n-3$ fatty acids in pregnant women. Br J Nutr 73, 387-395.

21. Oken E, Guthrie LB, Bloomingdale A et al. (2013) A pilot randomized controlled trial to promote healthful fish consumption during pregnancy: the Food for Thought Study. Nutr J 12, 33.

22. Rifas-Shiman SL, Willett WC, Lobb R et al. (2001) PrimeScreen, a brief dietary screening tool: reproducibility and comparability with both a longer food frequency questionnaire and biomarkers. Public Health Nutr 4, 249-254.

23. Oken E, Kleinman KP, Olsen SF et al. (2004) Associations of seafood and elongated $n-3$ fatty acid intake with fetal growth and length of gestation: results from a US pregnancy cohort. Am J Epidemiol 160, 774-783.

24. Oken E, Ning Y, Rifas-Shiman SL et al. (2007) Diet during pregnancy and risk of preeclampsia or gestational hypertension. Ann Epidemiol 17, 663-668.
25. Iso H, Rexrode KM, Stampfer MJ et al. (2001) Intake of fish and omega-3 fatty acids and risk of stroke in women. JAMA 285, 304-312.

26. Hu FB, Bronner L, Willett WC et al. (2002) Fish and omega3 fatty acid intake and risk of coronary heart disease in women. JAMA 287, 1815-1821.

27. Rifas-Shiman SL, Rich-Edwards JW, Kleinman KP et al. (2009) Dietary quality during pregnancy varies by maternal characteristics in Project Viva: a US cohort. J Am Diet Assoc 109, 1004-1011.

28. Schober SE, Sinks TH, Jones RL et al. (2003) Blood mercury levels in US children and women of childbearing age, 1999-2000. JAMA 289, 1667-1674

29. Bloomingdale A, Guthrie LB, Price S et al. (2010) A qualitative study of fish consumption during pregnancy. Am J Clin Nutr 92, 1234-1240.

30. US Department of Agriculture (2011) USDA National Nutrient Database for Standard Reference, Release 24. http://www.ars.usda.gov/services/docs.htm?docid $=8964$ (accessed January 2013).

31. Food and Drug Administration (2011) Mercury Levels in Commercial Fish and Shellfish (1990-2010). http:// www.fda.gov/food/foodsafety/product-specificinformation/ seafood/foodbornepathogenscontaminants/methylmercury/ ucm115644.htm (accessed January 2013).

32. Groth E 3rd (2010) Ranking the contributions of commercial fish and shellfish varieties to mercury exposure in the United States: implications for risk communication. Environ Res 110, 226-236.

33. Hu FB, Rimm E, Smith-Warner SA et al. (1999) Reproducibility and validity of dietary patterns assessed with a food-frequency questionnaire. Am J Clin Nutr 69, 243-249.

34. Rifas-Shiman SL, Fawzi W, Rich-Edwards JW et al. (2000) Validity of a semi-quantitative food frequency questionnaire (SFFQ) during early pregnancy. Paediatr Perinatal Epidemiol 14, A25-A26.

35. Donahue SM, Rifas-Shiman SL, Olsen SF et al. (2009) Associations of maternal prenatal dietary intake of $n-3$ and $n-6$ fatty acids with maternal and umbilical cord blood levels. Prostaglandins Leukot Essent Fatty Acids 80, 289-296.

36. National Research Council (2000) Toxicological Effects of Methylmercury. Washington, DC: National Academy Press.

37. Morrissette J, Takser L, St-Amour G et al. (2004) Temporal variation of blood and hair mercury levels in pregnancy in relation to fish consumption history in a population living along the St. Lawrence River. Environ Res 95, 363-374.

38. Baylin A, Kabagambe EK, Siles X et al. (2002) Adipose tissue biomarkers of fatty acid intake. Am J Clin Nutr $\mathbf{7 6}$, 750-757.

39. Bland JM \& Altman DG (1999) Measuring agreement in method comparison studies. Stat Methods Med Res 8, $135-160$.

40. Food and Drug Administration (2004) What You Need to Know About Mercury in Fish and Shellfish (Brochure). http://www.fda.gov/downloads/Food/ResourcesForYou/ Consumers/UCM182158.pdf (accessed November 2011).

41. Sunderland EM (2007) Mercury exposure from domestic and imported estuarine and marine fish in the US seafood market. Environ Health Perspect 115, 235-242.

42. Food and Drug Administration (2012) Total Diet Study. April 2001; Updated July 2008, January 2011, February 2012. http://www.fda.gov/Food/FoodSafety/FoodContaminants Adulteration/TotalDietStudy/ucm184293.htm (accessed March 2012).

43. Wall R, Ross RP, Fitzgerald GF et al. (2010) Fatty acids from fish: the anti-inflammatory potential of long-chain omega-3 fatty acids. Nutr Rev 68, 280-289.

44. Baylin A, Kim MK, Donovan-Palmer A et al. (2005) Fasting whole blood as a biomarker of essential fatty acid intake in 
epidemiologic studies: comparison with adipose tissue and plasma. Am J Epidemiol 162, 373-381.

45. Willett W (1998) Nutritional Epidemiology. New York: Oxford University Press.

46. Willett WC, Sampson L, Stampfer MJ et al. (1985) Reproducibility and validity of a semiquantitative food frequency questionnaire. Am J Epidemiol 122, 51-65.

47. Hibbeln JR, Davis JM, Steer C et al. (2007) Maternal seafood consumption in pregnancy and neurodevelopmental outcomes in childhood (ALSPAC study): an observational cohort study. Lancet 369, 578-585.

48. Tamburlini G \& Barbone F (2007) Maternal fish consumption and children's development. Lancet 369, 1166-1167.

49. Stern AH \& Rice DC (2007) Maternal seafood consumption and children's development. Lancet 370, 217-218.

50. Groth E 3rd (2008) Re: 'Maternal fish intake during pregnancy, blood mercury levels, and child cognition at age 3 years in a US cohort'. Am J Epidemiol 168, 236. 